\title{
Historical Cloisters and Courtyards as Quiet Areas
}

\author{
Massimiliano Masullo *(D), Francesca Castanò, Roxana Adina Toma and Luigi Maffei \\ Department of Architecture and Industrial Design, Università degli Studi della Campania "Luigi Vanvitelli", \\ 81031 Aversa (CE), Italy; francesca.castano@unicampania.it (F.C.); roxanaadina.toma@unicampania.it (R.A.T.); \\ luigi.maffei@unicampania.it (L.M.) \\ * Correspondence: massimiliano.masullo@unicampania.it
}

Received: 21 January 2020; Accepted: 3 March 2020; Published: 4 April 2020

\begin{abstract}
Searching for renovating and/or constructing quiet areas in historical urban sites, along with the conservation and valorization policies of the tangible and intangible value of historic urban sites are goals that can be combined into a unique sustainable strategy for the preservation of the sense of place and identity of communities as well as their well-being. Historic cloisters and courtyards are examples of such sites. Due to their physical, architectural, environmental and cultural features, they present restorative capabilities that could qualify them as quite areas. This paper aims to establish a new procedure that, through the exploration and analysis of past and current aspects of these sites, makes it possible to classify them and understand whether they still preserve a restorative character. A graphic representation, obtained from a historical analysis and an objective description of past and current historical/architectural, environmental and cultural scenarios, has been used. The results were compared with those of the Perceived Restorativeness Scale (PRS-11). A diamond shape represents highly restorative sites, while deviations from this shape were found to be weakly correlated with a restorative nature. This has also been shown by the high positive correlation of analytical parameters with the PRS-11 score and, in particular, with the component of Fascination.
\end{abstract}

Keywords: cloisters 1; courtyards 2; quiet areas 3; soundscape 4; restorativeness 5; preservations 6

\section{Introduction}

Over the last two decades, governments, agencies and scientific and technical communities have paid a deal of significant attention to the management of, and reducing noise pollution in, densely populated cities. For the first time, the European Community (EU) also introduced the concept of "Quiet areas", i.e., its regulations concerning zones that are not exposed to unwanted or unhealthy sounds [1,2] and that therefore serve as places where to escape, physically and psychologically, from the stress and chaos of the city. However, the European Environmental Agency EEA identified a relatively low level of accessibility to quiet areas for the population in cities above 50,000 inhabitants in Europe [3].

Searching for, renovating and/or building and making available, new quiet areas for people who live in densely populated cities are therefore important significant goals and challenges for both public and private, stakeholders, who must pay more attention to the implementation of sustainable policies that satisfy the environmental and quality-of-life requirements of the citizens.

To achieve these goals, a great deal of study in the field of environmental acoustics have focused on the characterization and preservation of the soundscapes of these areas [4-6], along with an analysis of the factors which can modulate well-being [7].

For the first aspect, following Schafer's ideas [8,9], the soundscape approach identifies the acoustic environment not only according to acoustic measurements (e.g., SPLs, spectral content, and time-variation) but also to how it is perceived by individuals according to several dimensions (e.g., pleasantness and eventfulness [10]). 
Regarding the second aspect, studies on noise perception and factors that modulate well-being have highlighted the positive effects that some environmental elements can have on human perception and noise annoyance. Green elements (e.g., trees, grass) [11,12], water elements (e.g., fountains, water-tanks) [13-15], and combinations thereof [16-19], have been shown to be well correlated to pleasantness and wellbeing. Most of these studies [20-23] investigated the restorative value of spaces through Kaplan's Attention Restoration Theory (ART) [24], using the Perceived Restorativeness Scale proposed by Hartig [25], or its variations [26-28]. The cognitive framework of ART concern with the recovery from mental fatigue or directed attention fatigue [29]. According to this theory an environment is restorative if it is rich in fascinating features, is perceived as coherently ordered and of substantial scope, and is compatible with what the individual wants to do [30].

With reference to big and historical cities, another big goal and challenge for public and private stakeholders is the incorporation, according to the "Recommendation on the Historic Urban Landscape" [31] of the United Nations Educational Scientific and Cultural Organization (UNESCO), of historic urban area conservation, management, and planning strategies into local development processes and urban planning. UNESCO defines the concept of the Historical Urban Landscape as being the result of a historic layering of cultural and natural values, as well as attributes that include the wider urban context and its geographical setting. According to this view, historical urban areas are exposed to several pressure factors (i.e., urbanization and globalization, economic development, and environmental issues). This has led to new opportunities, including the conservation of historical and the preservation of the sense of place of the sites, the identity of communities, as well as their well-being. "Knowledge and planning tools" could help to protect the integrity and authenticity of urban heritage, recognize cultural significance and diversity, and provide monitoring and management of changes, thus which are improving the quality of life and urban spaces.

Several researchers have investigated the effects that historical/architectural elements can have on different aspects of human health and behavior [32-34]. A literature review by Weber and Trojan [35] showed how historical/architectural elements can have a restorative value. Among the studies, Fornara and Troffa [36], administering the Perceived Restorativeness Scale [25] and the Scale of Affective Qualities of Places [37] to 197 participants, found that historical sites and urban parks were perceived to be restorative, pleasant, and relaxing. Analyzing the restorative capability of a Benedictine monastery on 521 visitors, Ouellette et al. [38] showed that beauty and spirituality gave rise to feelings of satisfaction and peace, while "being out" was correlated with satisfaction only for first time visitors. More recently, Grossi et al. [39] studied a group of 100 volunteers exposed to an intense cultural and aesthetic experience, highlighting how this had had a noticeable impact on individual physical and mental health.

All of the above-mentioned findings suggest that the environmental and historical/architectural elements should be considered when evaluating the human experience within complex urban spaces.

This paper, presents a strategy which can optimize the environmental, economic, architectural, and cultural resources inside cities, and that merges two apparently different goals (i.e., the need for quiet areas in urban sites and the need for the physical and cultural conservation of historical sites) into one unique, sustainable project. The strategy takes into account the broad definition of "quietness" as a mental and psychophysical concept of a restorative environment, based on the absence of perceived social and physical demands (e.g., crowds, noise) and the qualities of the environment. The sites that have been analyzed for use as oases which can improve people's quality of life and well-being are historical courtyards and cloisters, which are common in almost all ancient cities. With their architectural conformation, they ensure visual and acoustic insulation from the frenetic life outside [40-42]. At the same time, with the voices of shopkeepers peddling their merchandise, the craftsmen that sit outside their workshops, the artists who are performing, and so on, they are an active part of the perceived sound environment. With the removal of some physical s, along changes of usage, some features which made these places suitable for restoration and refuge have been lost. All these features, which are part of the intangible heritage of these sites, need to be analyzed and preserved. 
The exploration and analysis of the past and current aspects of the courtyards and cloisters, that allows us to classify them and understand whether they still conserve some restorative character, are based on a new procedure presented by the authors. An analysis of the historical/architectural and environmental aspects, as well as of the activities and the soundscape, of the sites is performed. For each site, acoustic recordings and subjective measurement of restorativeness are carried out. The validity of this new procedure has then been tested, by comparing the results of graphical representations with those of the Italian version of the Perceived Restorativeness Scale (PRS-11) [27].

As a case study, the procedure was applied to the ancient part of the city of Naples, and in particular, to two historical cloisters and two ancient courtyards, i.e., cloisters of Santi Marcellino e Festo and Sant'Andrea delle Dame, and the courtyards of buildings, the Palazzo Marigliano and the Palazzo Venezia.

Naples presents several peculiarities that are important for the first application of the procedure. It is characterized by a rich history, a lot of palaces, monasteries, churches strictly connected to courtyards, cloisters and urban gardens that often are sheltered from the overcrowded surrounding areas and streets. The Neapolitan Forma Urbis is unique with unusual architectural combinations and apparent contradictions. On the matrix of the ancient city clearly marked by the main Decumani and the network of Cardini, the paths, the spaces and the urban corners are almost the same as in the past. The Neapolitan architecture, particularly in the historic centre, is not pure construction, but continuous stratification around the original elements. In the same way, the most strident acoustic notes of the contemporary city overlap with the background sound themes, typical of ancient times. The city's climate has remained in many ways the same over the centuries when considering that a residual part of the daily life and productive activities are relatively unchanged, along with the bustle created by the crowd of the local inhabitants mixed, today, with many foreign tourists. Although amplified by modernity, inherently noisy and thundering, screaming and sometimes melodious, the sounds and noises are unchanged.

\section{Materials and Methods}

To analyze if the sites, such as the selected cloisters and courtyards of the historical palaces, still preserve restorative potentialities as in the past, a radar graphical representation at four dimensions of the aspects discussed above: Historical/Architectural, Environmental, Activities and Soundscape, were used. It is expected that a wide "Diamond" shape of this representation will be well correlated to the restorative sites. The details of the procedure, the scoring and the parameters used to validate the procedure are discussed in the sections below.

\subsection{Materials}

\subsubsection{Historical Investigation}

To investigate the historical context of the site in analysis, a bibliographic research must be carried out by history experts, since they can recognize the presence of green and blue elements as well as estimate the characters of the soundscape and activities of the past scenarios through the description of historical sources.

\subsubsection{Materials of the Objective Survey}

The objective survey focused on the characterization of four aspects:

- History/Architecture (HA) and Environment (ENV);

- Activities $(A C T)$ and Soundscape $(S O U)$ inside the sites and outside, in the surrounding area;

in the actual scenario.

The History/Architecture, Environment and Activities characteristics were collected through specific forms, that experts used during their exploration and analysis of the sites. The forms were 
obtained by an interactive process that defined the contents of the objective survey. Experts from the disciplines of history of architecture, cultural heritage and psycho-environmental research were involved. In a first phase, multimedia material collected during previous studies on quiet areas [40,41] was presented ( 2 times) to the experts who filled in an open form where they wrote the attributes, they considered relevant for each aspect. In the second phase, the experts defined the expected levels of each of the selected attributes ( 2 times). Finally, they visited the sites and rated each attribute according to the final objective survey sheet ( 3 times at different times of the day) (see Table 1). The description of each attributes is presented below:

The History/Architecture form investigated three main attributes:

- Dimension $(D)$ : The dimension of the site has a great importance on the use of the spaces, on the distribution of the sound sources, on the sound propagation and separation of inner from outer spaces. Large dimensions are potentially associated to increasing availability of restorative areas inside the sites.

- Protective Entrances (PE): PE is important due to two main aspects: PE1) Entrances with long arcs/tunnels lead to backward cloisters in relation to the outside noises; PE2) The presence of big doors provides a high sound insulation of the inner spaces. High PE values are expected to be positively correlated to the reduction of the external noise inside the sites.

- Cultural Value (CV): $C V$ gives information about the richness of the contents and historical relevance of the site, as well as the cultural functions it hosts. All these elements enhance the sense of people of being-away from the everyday routine, to perceive the place, as a "whole other world" and hold individual attention [24,29]. High CV values are expected to be correlated to a high Restorativeness perception.

$D, P E$ and $C V$ are assumed to have the same weight to determine the magnitude of the History/Architecture dimension.

The Environment form investigated two attributes:

- Water Elements (WE): The number and typologies of water elements (fountains, water-tanks) have been shown to have a significant influence on human perception, as well as on informational masking. The vision of water movement, the feeling of freshness and its natural sounds, provide a general improvement on people's well-being.

- Green Elements (GE): Like the water elements, the extension and typologies of green elements, such as grass or trees, provide a general improvement on people's well-being.

Both the previous characteristics are positively correlated with the perceived restoration of the sites. WE and GE are assumed to have the same weight to determine the magnitude of the Environment dimension. In contrast to the previous variables, which can be considered substantially invariable over a short time, the remaining two change continuously and need to be collected and averaged over several assessments during the day.

The activities were measured by means of in situ observations by the experts who filled in a specific Activities form. It analyzed three main attributes:

- Typologies of activities (T): Since different categories of activities can affect the perception of the site, the main typologies of activities that take place inside the site are identified. Three levels of the activities are distinguished: None, Personal (daily life activities) and Productive (handcraft/commercial). Since the typology of activities passes from None to Handcraft/Commercial, it is expected that the site becomes less restorative.

- Intensity of activities (I): Due to the influence that the intensity of the activities can have on the perception of the sites, an estimation of this attribute is carried out. High activities are referred to as very busy sites. Low, to the absence or to very slow activities (e.g., meditation, reading); High intensity is expected to negatively affect the perception of the Restorativeness. 
- Accessibility $(A C)$ : The last attribute takes into account the possibility for visitors, citizens or tourists, to go inside the site. Three levels of the accessibility are considered: No access, Restricted access due to limitation to groups of individuals or to fee access, and Free access. As above, free accessibility is expected to be negatively correlated with the restoration of the sites.

$T, I$ and $A C$ are assumed to have the same weight to determine the magnitude of the Activities dimension.

Table 1. Objective Survey Sheet.

\begin{tabular}{l}
\hline Dimension of The Area (D) (tick with an $\mathrm{x}$ ) \\
\hline Big \\
Medium \\
Small \\
\hline Existence of Protective Entrances (PE) (tick with an $\mathrm{x}$ ) \\
\hline Yes \\
No \\
\hline Please Describe the Characteristics of Protective Entrances: \\
\hline Existence of Elements of Cultural Value (CV) (tick with an $\mathrm{x})$ \\
\hline Yes \\
No \\
\hline Please Describe the Main Characteristics of the Cultural Elements: \\
\hline Presence of Elements That Use Water Such as Fountains or Small Basins (WE) (tick with an x) \\
\hline Yes \\
No \\
\hline Please Describe the Elements: \\
\hline Presence of Green Elements Such as Grass or Trees (GE) (tick with an x) \\
\hline Yes \\
No \\
\hline Kind of Green Elements: \\
\hline Intensity of the Activities Inside the Area (I) (tick with an x) \\
\hline High \\
Medium \\
Low \\
Please Describe the Typology of the Observed Activity (T): \\
Yossibility for Visitors, Citizens or Tourists, to Have Free Access to The Area (AC) (tick with an x) \\
No \\
\hline
\end{tabular}

The Soundscape measurements consist of binaural recordings inside the site and outside, in the surrounding area.

- Inner soundscape measurements: These measurements aim to characterize the sound levels inside the site. They consist of spot sound measurements of at least $4 \mathrm{~min}$, in different positions inside the site. This duration is representative of the succession of auditory events;

- Outer soundscape measurements: These measurements aim to characterize the sound levels outside the site under investigation. They consist of soundwalks of about $3 \mathrm{~min}$, from and to the sites, in two opposite directions of the road. The duration of the measurements corresponds to path lengths of about $180 \mathrm{~m}$ at a walking speed of about $1 \mathrm{~m} / \mathrm{s}$. This time/length is sufficiently large to be representative of the temporal and spatial changes of soundscape outside the sites.

Since it is impossible to make measurements of the past sound levels, a qualitative scale that estimates the sound levels as Low (1pts), Medium (2 pts) and High (3 pts) from the historical analyses is proposed and used. The level High is associated to loud activities that involve the presence of sellers 
shouting and the use of heavy mechanical tools and machines. Medium is associated to the presence of at least some handcraft activities and the movements of carriages and horses. Low is associated only to very quiet activities.

To compare the current and past scenarios of the sites, only two different soundscape attributes are used:

- Sound Levels Difference (SLD): It is based on the assessment of the outside-to-inside differences of measured ( $\mathrm{L}_{\text {eqA,Outside }}-\mathrm{L}_{\text {eqA,Inside }}$ in current scenario) and estimated ( $\mathrm{L}_{\text {Outside }}-\mathrm{L}_{\text {Inside }}$ in past scenario) sound levels. The lower the difference is, the higher the soundscapes are expected to be restorative.

- Pleasantness of sounds (PS): This characteristic assigns scores to the quality of the soundscape. PS. Three levels of pleasantness have been considered for soundscapes with prevailing mechanical, anthropic and natural sounds. higher values of $P S$ are associated to restorative environments.

SLD and PS are assumed to have the same weight to determine the magnitude of the Soundscape dimension.

\subsubsection{Scoring of the Objective Survey}

Different qualitative scales were associated to each attribute of the four variables. The description of the levels of each attribute and the corresponding scores are shown below.

History/Architecture

- Dimension $(D)$ has three levels: Small (0 pts), with area $<500 \mathrm{~m}^{2}$; Medium $(1 \mathrm{pts})$, with area between 500 and $1500 \mathrm{~m}^{2}$; Large (2 pts), with area $>1500 \mathrm{~m}^{2}$;

- Protective Entrances (PE) is the sum of PE1 and PE2. PE1 has two sub-levels: without (0 pts) and with (1 pts) long arc/tunnel and PE2 has two levels, i.e., without (0 pts) and with (1 pts) big doors;

- Cultural Value (CV) may assume three levels: without (0 pts), with some (1 pts) or with several (2 pts) elements of cultural value.

$H A$ variable is calculated by the sum of the previous attributes and can assume values in the range 0 to 6.

$$
H A=D+P E+C V
$$

Environment

- Water Elements (WE): has three levels: without water elements (1 pts), with water-tanks (2 pts) and fountains (3 pts);

- Green Elements (GE): may assume three levels: without (1 pts) and with few (2 pts) and several (3 pts), green elements.

The $E N V$ variable is calculated by the sum of the previous attributes and can assume values in the range 1 to 6 .

$$
E N V=W E+G E
$$

Activities:

- Typologies (TA) consider three level: None (0), Domestic (1) and Productive (2);

- Intensity (IA) may have three levels: Low (0), Medium (1) and High (2).

- Accessibility (ACC) has three levels: No access (0), Restricted access (1), Free access (2).

The ACT variable is calculated by the sum of the previous attributes and can assume values in the range 0 to 6 .

$$
A C T=T A \times I A+A C C
$$


Soundscape:

- $\quad$ Sound Levels Difference (SLD) has three levels: High (1 pts), Med (2 pts) and Low (3 pts), that corresponds, respectively, to measured differences $\mathrm{L}_{\text {eqA,Outside }}-\mathrm{L}_{\text {eqA,Inside }}$ (current scenario) of: $>$ $9 \mathrm{~dB}(1 \mathrm{pts}) ;>9$ and $\leq 3 \mathrm{~dB}(2 \mathrm{pts}) ; \leq 3 \mathrm{~dB}$ ( $3 \mathrm{pts}) ;$ or to estimated differences of Loutside $-\mathrm{L}_{\text {Inside }}$ (past scenario): i.e., 2 (1 pts), 1 ( 2 pts) and 0 ( 3 pts).

- Pleasantness of sounds (PS) has three levels Low, soundscape with prevailing mechanical sounds (1), medium soundscape with prevailing anthropic sounds (2) and, high soundscape with prevailing natural sounds (3) pleasantness of sound environment.

The $S O U$ variable is calculated by the sum of the previous attributes and can assume values in the range 1 to 6 .

$$
S O U=S L D+P S
$$

Table 2 summarizes the scoring of each variables and attributes with the respective formulae and score range.

Table 2. Scores of Diamond Procedure.

\begin{tabular}{|c|c|c|c|c|}
\hline Variable & & Attributes & & Formula \\
\hline Historic/Architecture, $H A$ & $\mathrm{D}(0,1,2)$ & $\mathrm{PE}(0,1,2)$ & $\mathrm{CV}(0,1,2)$ & $H A=D+P E+C V$ \\
\hline Environment, ENV & WE $(1,2,3)$ & $\operatorname{GE}(1,2,3)$ & & $E N V=W E+G E$ \\
\hline Activities, $A C T$ & $\mathrm{TA}(0,1,2)$ & IA $(0,1,2)$ & $\operatorname{ACC}(0,1,2)$ & $A C T=T A \times I A+A C C$ \\
\hline Soundscape, SOU & $\operatorname{SLD}(1,2,3)$ & PS $(1,2,3)$ & & $S O=S L D+P S$ \\
\hline
\end{tabular}

\subsubsection{Subjective Survey}

The survey is used to describe, in the current scenario, the Restorativeness level of each site. To this aim, a Perceived Restorative Scale should be administered to a representative sample of people during subjective survey, in situ.

\subsection{Procedure}

Once the historical period has been identified, the scores for the past scenario are assigned based on the historical analyses of the sites on:

1) Tangible heritage

2) Activities and Uses

While historical studies on the tangible heritage allows to assign scores to the $H A$ and $E N V$ variables, those on the Activities and Uses, and of the surrounding areas, are used to estimate the $A C T$ and $\mathrm{SOU}$ variables.

In contrast, the scores for the current scenario are assigned according to the results of the objective survey made in situ by the experts. The Activities, Historic/Architecture and Environmental variables are measured qualitatively by the specific forms, while the Soundscape is measured in different periods of the day and then averaged.

The representation of the results on a four-dimensional graph is used to classify the sites with Low or High Restorativeness. Diamond shapes (D shape) with a favorable Soundscape (6 pts), high value of History/Architecture (6 pts), with several Environmental elements (6 pts) and with moderate or low level of activities ( $<3$ pts) effectively describe a high Restorative environment.

\subsection{Validation}

In the current situation, the outputs of this procedure have then been compared with those obtained by the PRS-11 during subjective surveys for its validation. For the comparison, two factors which analytically describe the similarity between the graphical representations of the different sites have 
been introduced. The first describes the ratio among the four variables of the procedure, $F_{\text {shape, }}$ while the second, $F_{m a g}$, the global magnitude of all the components.

$$
\begin{gathered}
\mathrm{F}_{\text {shape }}=\frac{A C T+H A}{S O U+E N V} \\
\mathrm{~F}_{\text {mag }}=\frac{(A C T+H A) \times(S O U+E N V)}{2}
\end{gathered}
$$

It is expected that wide Diamonds shapes provide a good equilibrium among the four variables $\left(F_{\text {shape }}=0.75\right)$ and a good power of Restorativeness $\left(F_{\text {mag }}=54\right)($ Figure 1$)$.

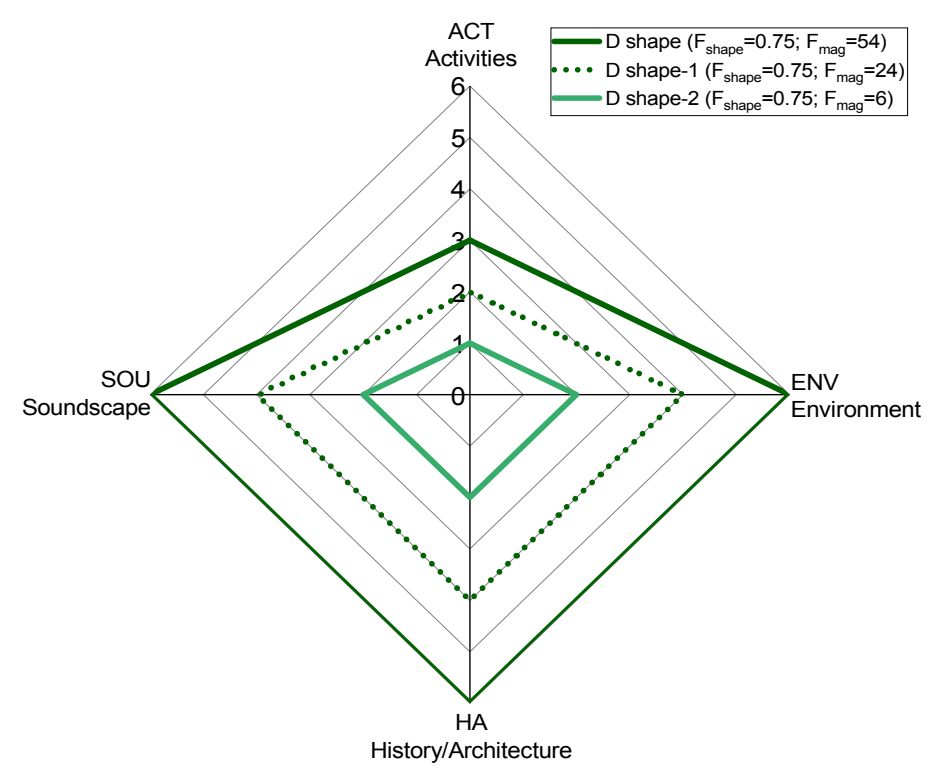

Figure 1. Graphical representation of a Diamond shape $\left(\mathrm{F}_{\text {shape }}=0.75\right)$ at different magnitude factors (D shape, $F_{m a g}=54 ; \mathrm{D}$ shape-1, $F_{m a g}=24$ and D shape-2, $F_{m a g}=6$;).

Moreover, the comparisons between the past and current outputs of the procedure have been used to investigate the state of conservation of the Restorativeness of the sites. Less the differences between the results of past and current scenario of the four variables are, the higher the state of conservation of the sites is. The comparisons can also be used to suggest and adopt new and sustainable conservation strategies of the sites.

\section{Case Study}

The historic Center of Naples (Figure 2). was selected as a case study. Along the rectangular grid layout of the ancient Greek foundation with its platêiai (the Roman Decumani) and stenōpói (the Roman Cardini), there are several historical palaces and churches with their own courtyards and cloisters. 2 cloisters (the cloister of Santi Marcellino e Festo and the Cloister of Sant'Andrea) and the historical courtyards of 2 palaces (Palazzo Marigliano e Palazzo Venezia) were selected for the study. To compare the present with the past, a specific historical period was chosen, the historical context of the survey is the Eighteenth Century, when Charles of Bourbon, the first king after years of vice-reign to inhabit the city, ascended to the throne of Naples. 

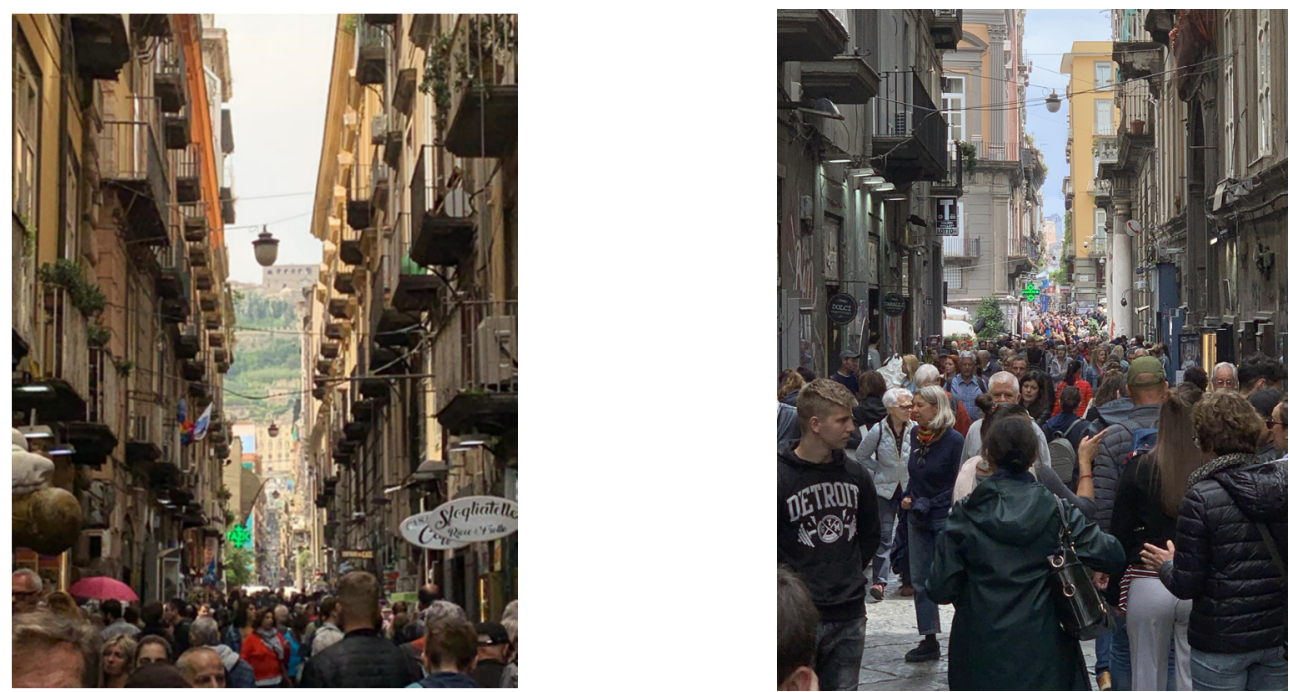

Figure 2. The historical city centre of Naples.

\section{Application of the Procedure}

\subsection{Historical Investigation}

The historical investigation was carried out for the four sites through the study of the historical documents, especially the guide of Naples "Delle Notizie del bello, dell'antico e del curioso della città di Napoli" [43] of Carlo Celano, where activities and uses, the sounds were investigated, along with the presence of any green and blue elements.

\subsubsection{Naples}

The strong link between the present day and the Eighteenth Century, defined by Giuseppe Galasso as the most beautiful time for Naples [44], can be found in the affirmation of the myth of progress, in new techniques and an emerging machinist spirit that affected the rhythms and functions of the city, but also in the demographic expansion, in the economic dynamism and in the cultural and social development.

In the eighteenth century, the European nature, never assumed before, led Naples to conquer the new role of metropolis, in the context of a state power increasingly detached from the religious and feudal systems, linked to the ascent of the Bourgeoisie.

The profound change in economic structures, deriving from the new fervor of the political and social life of the Kingdom, determined the growing privatization of ecclesiastical properties and the consistent increase of a productive and rampant middle class, made up of merchants, financiers, togated people, but also of workers, craftsmen, businessmen and the static rhythms of country life were countered by the feverish life of the growing city [45].

In the middle of the eighteenth century, 450,000 inhabitants lived in the capital of the Kingdom and most of the productive activities, trade and markets were located in the heart of the city centre or in its immediate surroundings.

Opportunities for exchange, meeting, sale and consumption of goods invaded public space, increasing exponentially. Carlo Celano in his guide of Naples "Delle Notizie del bello, dell'antico e del curioso della città di Napoli" [43] recorded numerous palaces and workshops in the street known as Monteoliveto and he reminded the reader of some predominant activities like the many small shops of the Librai from which the street would later take its name, or also of the Panettieri where once the bakers piled up bread, along with the numerous silk manufacturers, spinners, weavers and dyers, in addition to the Mannesi, the historical carpenters or repairers of carriages. 
However, there are still many problems linked to the difficult social relations and distribution of private property, still mainly managed by the ecclesiastical system and noble class. The extensive ecclesiastical heritage and one of the most important aristocratic families are concentrated in the city centre. During the eighteenth century, both the church and the nobility expanded their properties, saturating the space still available, both in the adjacent areas that remained free both in height, with complete reconstructions of the city's palaces, opening new rooms in the basement body or building entire floors above the existing ones.

Most of the conventual islands and noble palaces are along the grid of Decumani and Cardini. there are most of the conventual islands and noble palaces. Excluding the plot of streets and alleys, and the sparse squares and public open spaces, crowded with the presence of new activities and a growing number of people, the monastic orders and the aristocratic class elect the private space inside them as a restful island and an intimate place to live.

During the eighteenth century, many convent complexes of older foundations were expanded or transformed, and others were added [46].

In the distribution of monastic space, the churches represent, secularly, the meeting point between the believer and the faith, and therefore a place open to worship and the city, while the cloisters attached to them constitute the tangible boundary, the condition of isolation of the clergy from the secular world. Since the earliest times, they have limited their activities within the cloistered environment, the rituals carried out daily by the monks alone, separated from the bustling life of the outside world by a threshold, which only a few chosen ones can cross. On the lower floor of the cloister, there were generally the speakers, the service rooms, such as the kitchen, oven, pantry, laundry room, warehouses, as well as the pharmacy and refectory [47] above, there were the cells and accommodation of the clergy.

After the Council of Trent, during the Seventeenth Century, as an exception to the tightening of the confinement dictated by the enclosure, the Neapolitan cloisters lost the exclusive prerogatives of places of contemplation and absolute isolation, limiting the parts used as an orchard and garden, integrating with the surrounding urban environment, a loss of primary characteristic testified by the many "open cloisters", as in the case of the complex of Santi Marcellino e Festo. Islands of quiet, no longer for the exclusive use of religion, due to the presence of many lay people who were allowed access to the cloistered spaces. The friars themselves, and to a greater extent the nuns, forced to take their vows not by free choice but by family imposition, in the absence of an authentic vocation, faced conventual life without the necessary privations and the cloisters between the Eighteenth and Nineteenth Centuries were open to walks, celebrations and entertainment. Despite the prohibition on worldliness, in particular the female monasteries, such as Sant'Andrea delle Dame and Santi Marcellino e Festo, became cultural centres, where the voices of Neapolitan artists, who were welcomed here and given opportunities to work, were combined with religious songs.

\subsubsection{The Courtyards of Historical Palaces}

Palazzo Marigliano, once known as Palazzo di Capua, overlooks via San Biagio dei Librai, one of the most attractive streets in the eighteenth century due to the presence of the aristocracy and it being very central. This road is renowned as the street of booksellers due to the large number of bookshops. Since 1734 the street was home to the printing presses of Stefano Abbate, Novello de Bonis, Nicola Migliaccio, Nicola Monaco, Felice Mosca, Francesco Pepe, Secondino Porsile, Giovanni Rosiello and Antonio Vico.

In the past, the building was one the most significant aristocratic residences of the eighteenth century with specific environmental characteristics defined both by the greenness of the roof garden enriched by the prospective paintings realized by Antonio Alfano in 1756 and by the elements of artistical value like the tiles realized by Antonio Sciaretta for the new external staircase with a triple rampant leading to the roof garden and placed laterally to the courtyard, later moved by the Marigliano family frontally to the entrance hall [48]. During the Eighteenth century, the global extension of the garden and courtyard covered $576 \mathrm{~m}^{2}$. The soundscape of the internal courtyard is due to anthropic 
activities with Low levels estimated, rather than the external ones valued as High due for the large numbers of bookshops present at the time along Via San Biagio dei Librai.

Nowadays, as well as in the past, the building stands in a narrow and densely built up street and still preserves its original function of residence, while at the same time being the headquarters of the Archival and Bibliographic Surveillance of Campania and housing several small commercial activities such as the historical hospital for dolls which carries out quality craftsmanship (Figure 3). The site still preserves the entrance door with the decorated vault, the historical epigraphs and the statues but has lost its greenness. Its global extension has been reduced to $360 \mathrm{~m}^{2}$. The surrounding sonic environment seems to be characterized by a lower intensity of activities compared with the past and also seems more pleasant. The acoustic levels recorded in the courtyard are in the average $62.3 \mathrm{~dB}(\mathrm{~A})$, while the levels measured along the street, still full of bookshops and other commercial shops, are $71.7 \mathrm{~dB}(\mathrm{~A})$.

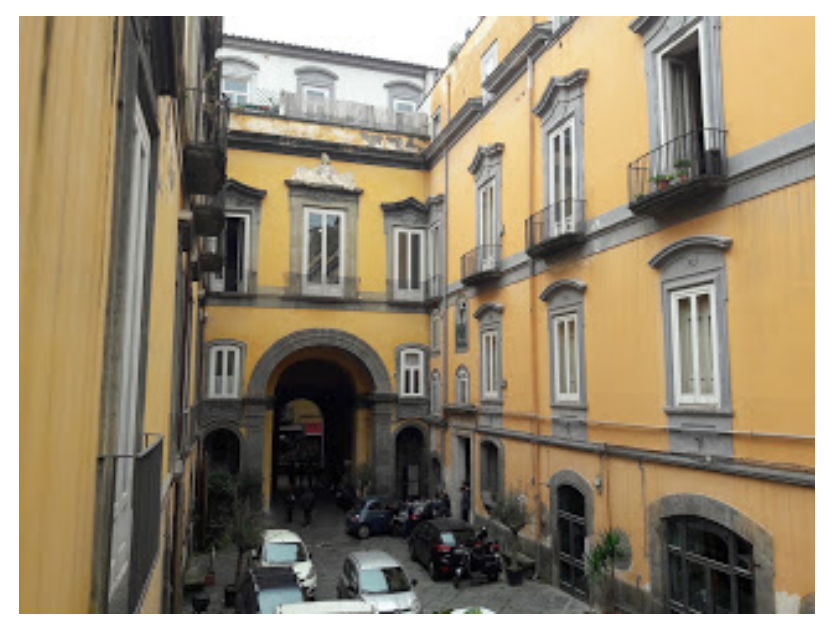

(a)

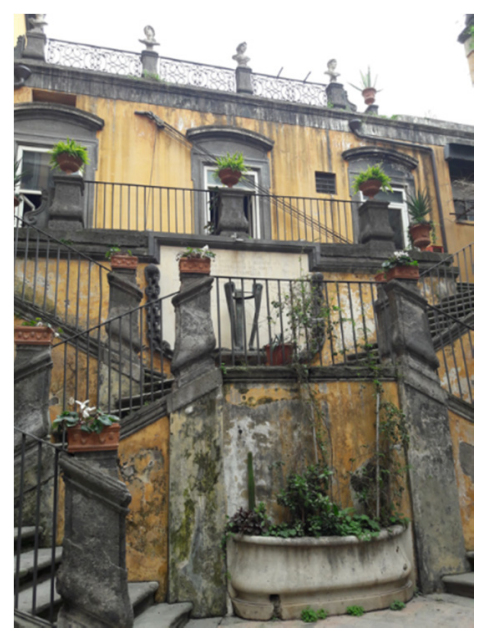

(b)

Figure 3. Palazzo Marigliano: (a) the inner courtyard; (b) the picturesque staircase.

Palazzo Venezia was not only a lively site but also of significant artistic and cultural value located in one of the most attractive roads in eighteenth century due to the presence of the aristocracy. Over the centuries Palazzo Venezia played an important role in the political and social life of the city: Corniani defined the building as one of the most noble and magnificent houses and Pietro Dolce highlighted the great visibility of the palace and its position in an area of considerable interest. Nevertheless, the building needed to be restored several times during the seventeenth century, recalled in the epigraphs, so as to reinforce the architectural structure. Over the years, the gardens and orchards, that originally surrounded the palace, were progressively reduced by the enlargement of the nearby palace of Filomarino. In 1706, the garden counted forty feet of citrus, oranges, lemons, acacias and about one hundred feet of fruits, while in nineteenth century it was impoverished compared to the past. From the bibliography, there are reports of, at the end of the Seventeenth Century of cellars, granaries, stables, a well and servants' quarters as well as the rooms rented to the zagarellaro and the copyist [49]. The soundscape seemed to be characterized by the human activities as well as the presence of blue elements like the well, in addition to the neighing of horses and the sounds of other domestic animals. The sound levels estimated inside the courtyard can be considered as Medium, whereas the external ones can be defined as High.

Nowadays, the hanging garden still preserves the ancient charm and fascinates the visitors due to the greenness and the beautiful Casina Pompeiana (Figure 4), while a lowered atrium precedes the entrance courtyard dominated on the left by the open staircase defined by a structure set on three arches. The first-floor houses an art gallery and café that overlooks a gorgeous terrace (Figure 5). Today the global extension of the garden and the courtyard is $375 \mathrm{~m}^{2}$. Additionally, the soundscape, due 
to a reduced activity intensity, seems to be more pleasant, with the measured sound levels being on average $62.6 \mathrm{~dB}(\mathrm{~A})$ inside the courtyards and $70.2 \mathrm{~dB}(\mathrm{~A})$ along via Benedetto Croce.

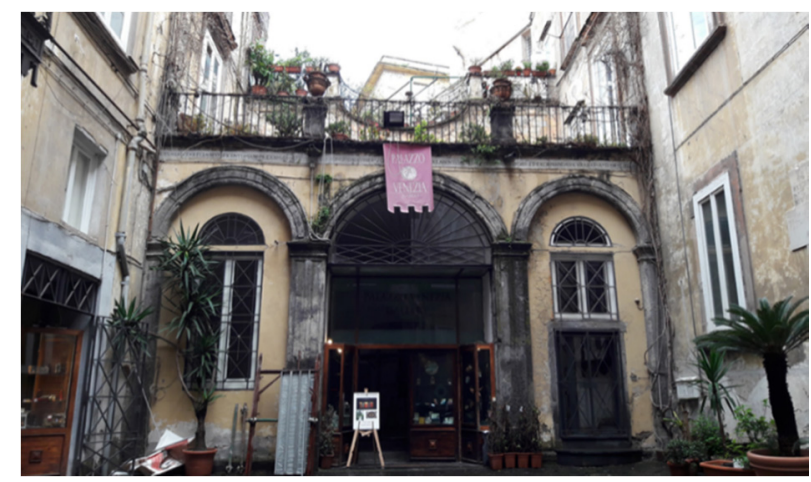

(a)

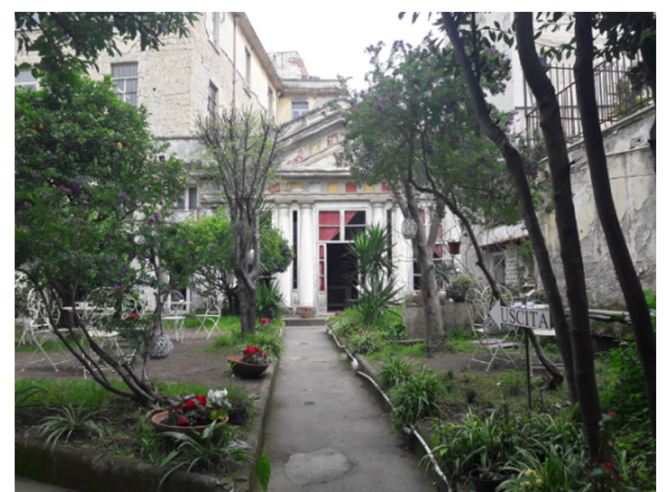

(b)

Figure 4. (a) The courtyard and (b) the Roof Garden of Palazzo Venezia.

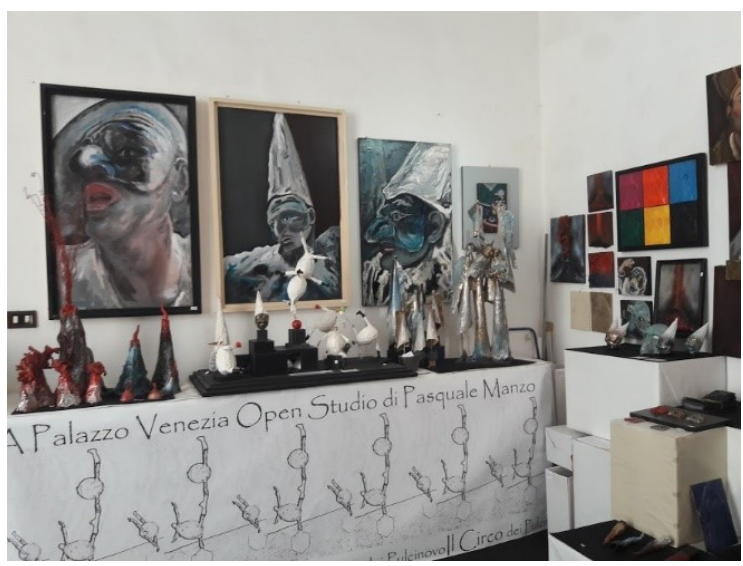

(a)

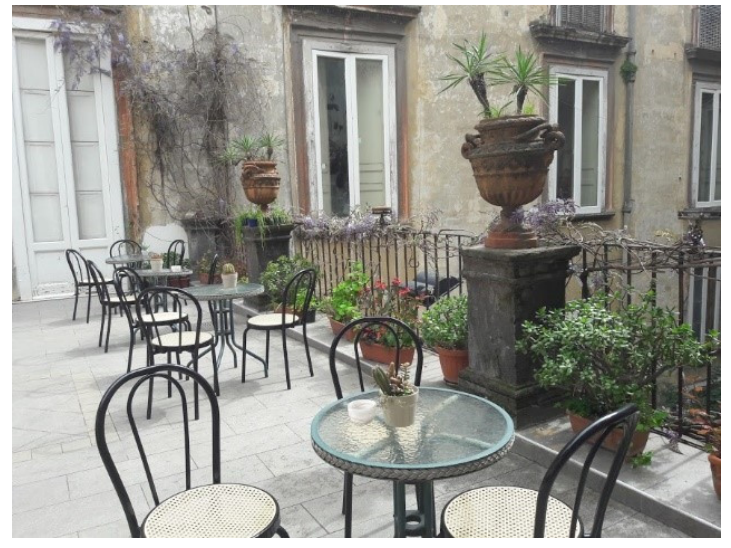

(b)

Figure 5. (a) The art gallery and (b) the café.

\subsubsection{The Cloisters}

The cloister of Saints Marcellino and Festo was defined by G. Ceci as a beautiful and sumptuous place and today still preserves the attractiveness of the past centuries. Built in 1565 when the monastery of Saints Marcellino and Pietro and Saints Festo and Desiderio were merged. The complex is characterized by the upper cloister which opens toward the sea with a botanical garden designed by Vincenzo della Monica that according to a survey conducted in 1992, counted different trees (Olive, Orange, Ficus, Eucalyptus, Holm oak, Yucca, Banana, Laurel, Myrtle, Mandarin, Magnolia, Medlar and others), shrubs (Oleander, Bosso, Spirea, Ligustro Ruscus) and by the lower cloister dominated by the magnificent staircase with two lateral rampants designed by Luigi Vanvitelli $[50,51]$ (Figure 6 ). In addition to the large extension $\left(3300 \mathrm{~m}^{2}\right)$, it also resulted sheltered from the surrounding streets by a double entrance gate connected with a corridor and rich with greenness and water elements due to the presence of gardens like the botanical one and the different fountains. The cloister was animated by the nuns during their daily activities of prayer, meditation and other intellectual activities.

The soundscape seemed to be pleasant and enhanced by the water sounds and the birds chirping, as well as by the scents of the flowers and citrus fruits. The sound levels can be estimated as low inside due to the quieter activities carried out, while the outside levels are valued as medium. 


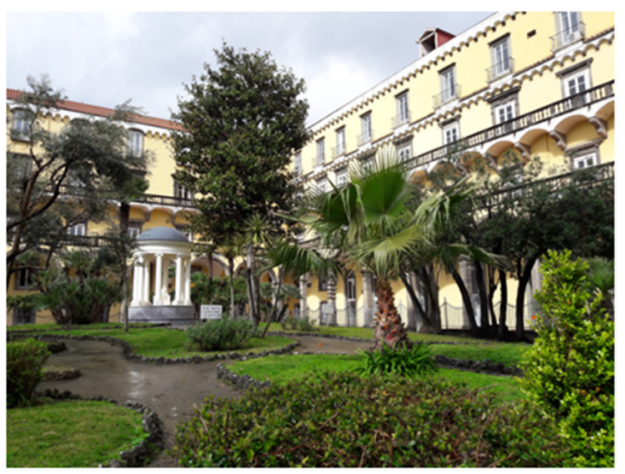

(a)

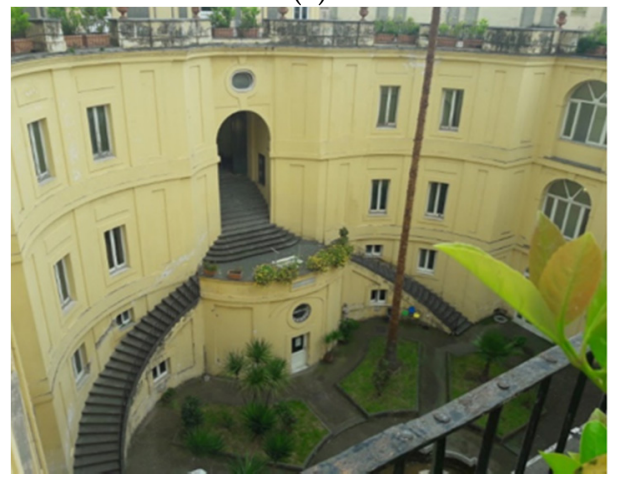

(b)

Figure 6. (a) the upper and (b) the lower Cloister of San Marcellino e Festo.

Today, it is freely accessible and captures the attention not only due to the beauty of the architectural structure, but also the presence of historical cultural elements such as the statue of the empress Augusta, or the two mullioned windows decorated with episodes of the new testaments, capitals and architectural elements coming from the suppressed convent of Saint Sebastiano as well as the seventeenth century fountain decorated with four dog heads and once located centrally (Figure 7). The view is also enhanced by the majolica dome of the church of San Marcellino adorned with a geometric rhombus pattern with a two-tone yellow-black color. The cloister preserves its extension and its cultural importance as well as the green and blue elements (Figure 8). On the contrary, the intensity of the activities is more relevant due to the free access to the site, with it being an attractive cultural center due to the presence of historical cultural elements and considering that it houses the Università degli Studi di Napoli Federico II and the Museum of Paleontology. The sound levels measured inside the cloister are on average $59.9 \mathrm{~dB}(\mathrm{~A})$, while the external levels are $70.0 \mathrm{~dB}(\mathrm{~A})$.

The monastery of Sant'Andrea delle Dame is described by Celano as one of the most beautiful and largest of the city $\left(2000 \mathrm{~m}^{2}\right)$. Moreover, he reported that it was one of the most well administered, richest and exemplary [43]. The religious complex in the eighteenth Century was highly desirable for the woman who wanted to follow a cloistered life ensured by the protective entrance realized with double doors, one internal and one external, simultaneously opened only in case of emergencies. The nuns that followed the rule of St. Augustine had further rules for several aspects of everyday life such as prayers, spiritual readings and songs, for example the Miserere, the De Profundis and the Requiem Eternam played every Friday before entering the chapter house. The monastery housed a workshop where the nuns worked for common well-being, while one of them read religious texts and prayers. There was also a pantry and infirmary [52]. Moreover, the beauty of the cloister and religious complex was due to the countless workers involved in its decoration like Pietro Mennes who realized the pillars of the cloistered courtyard, Belisario Corenzio who decorated the church with frescoes, Giovan Domenico Vinaccia who realized in the Seventeenth Century the marble shrine as well as 
Giovan Battista Cavagna who designed a doorway in piperno surmounted by a triangular tympanum decorated with the representation of the Madonna and the holy protectors of the Augustine order [53].

It is possible to estimate that the sound environment of the cloister was very pleasant with low levels, while the outside levels once again can be predicted as Medium. The pleasantness of the site was at the same time enriched by the artistic value of the complex as well as by the green elements and, considering that in general water is one of main characteristics of the cloisters, probably due to the presence of water elements that today can be seen. Nowadays the complex conserves its extension, the architectural characteristics and the protective entrances that shelter from the nearby trafficked streets. Over the years, it has lost the tranquility of the past and the sounds are not as pleasant even with the presence of green and blue elements (Figure 9). Today, there is the Department of Medicine which is frequented by numerous students on a daily basis. The acoustic measurements carried out show on average inside levels of $65.8 \mathrm{~dB}(\mathrm{~A})$ and outside levels of $71.9 \mathrm{~dB}(\mathrm{~A})$.

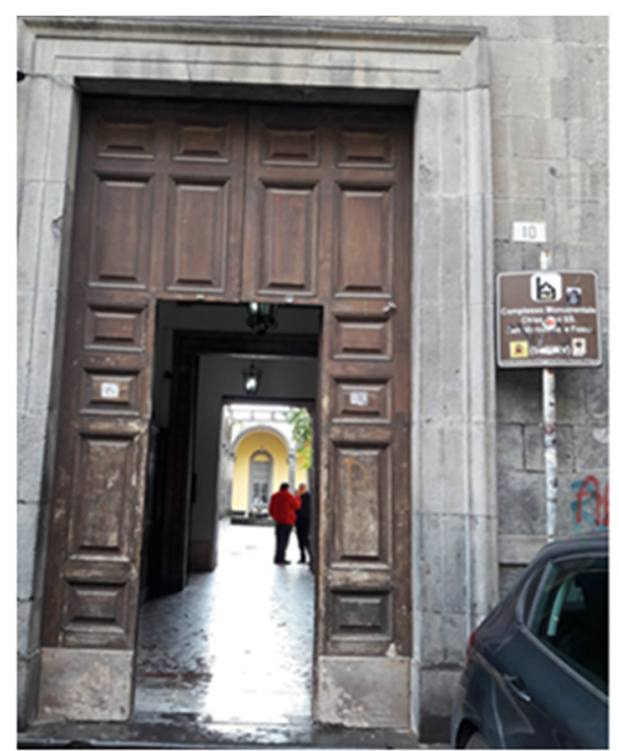

(a)

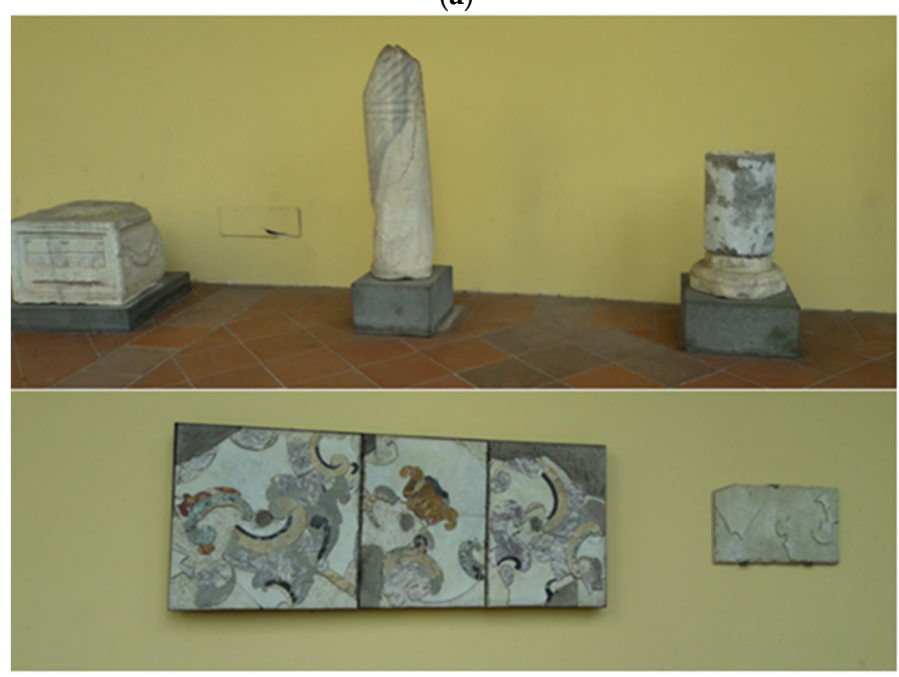

(b)

Figure 7. (a) The entrance gate, and (b) the cultural elements of Cloister of the Santi Marcellino e Festo. 

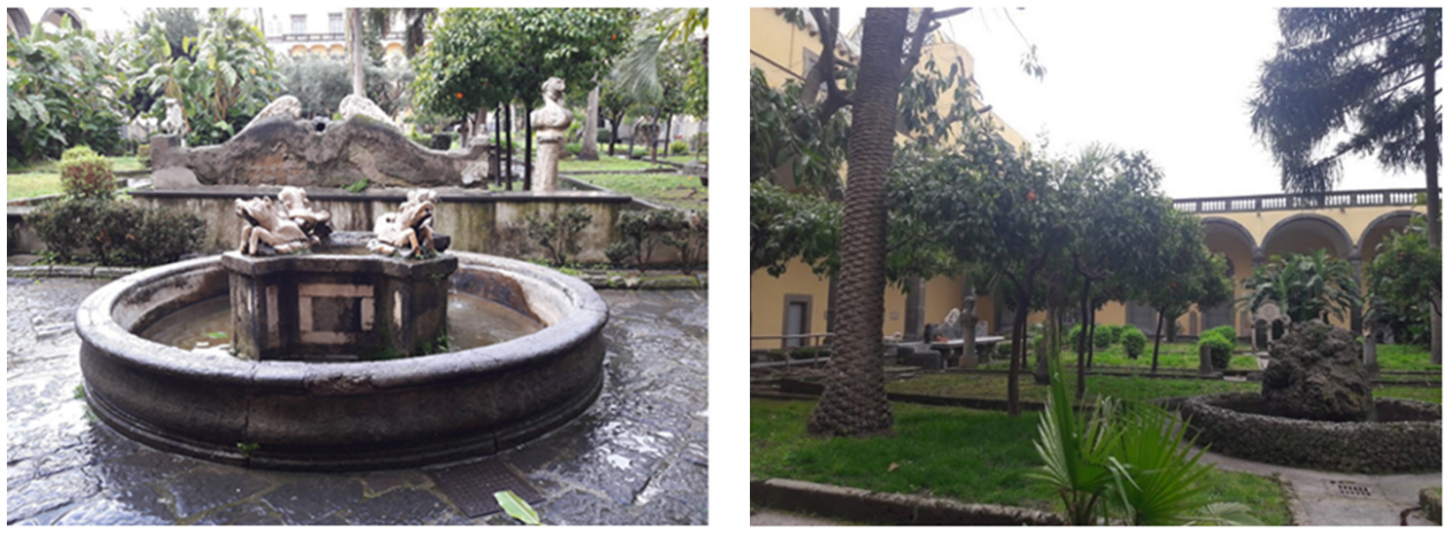

Figure 8. Fountains of Cloister of Santi Marcellino e Festo.
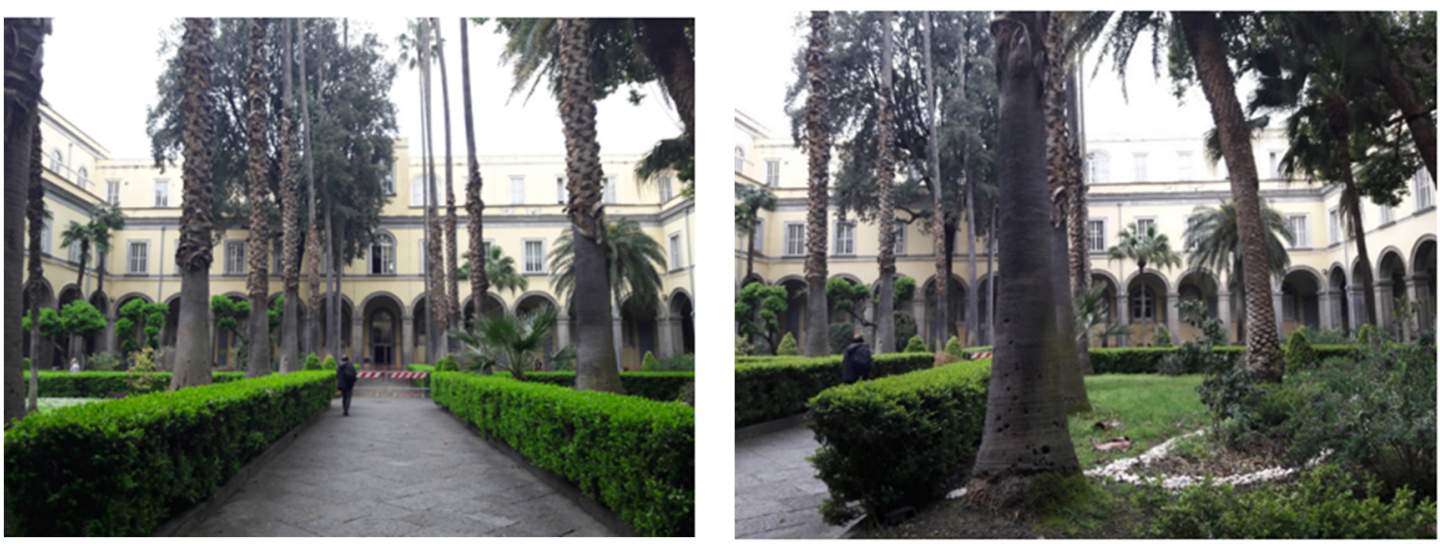

Figure 9. Cloister of Sant'Andrea delle Dame.

\subsection{Results}

The results of the analyses led to the assigning of scores to the past and current scenarios, for HA (Table 3), ENV (Table 4), ACT (Table 5), SOU (Table 6) and globally (Table 7).

Table 3. Historic/Architecture variable scores for the past and current scenarios.

\begin{tabular}{ccccccccc}
\hline & \multicolumn{4}{c}{ Past } & \multicolumn{5}{c}{ Current } \\
\hline Sites & D & PE & CV & HA & D & PE & CV & HA \\
\hline Santi Marcellino and Festo & 2 & 2 & 2 & 6 & 2 & 1 & 2 & 5 \\
Sant'Andrea delle Dame & 2 & 2 & 2 & 6 & 2 & 2 & 1 & 5 \\
Palazzo Venezia & 0 & 1 & 1 & 2 & 0 & 1 & 1 & 2 \\
Palazzo Marigliano & 1 & 1 & 1 & 3 & 0 & 1 & 1 & 2 \\
\hline
\end{tabular}

Table 4. Environment variable scores for the past and current scenarios.

\begin{tabular}{ccccccc}
\hline & \multicolumn{3}{c}{ Past } & \multicolumn{3}{c}{ Current } \\
\hline Sites & WE & GE & ENV & WE & GE & ENV \\
\hline Santi Marcellino and Festo & 3 & 3 & 6 & 3 & 3 & 6 \\
Sant'Andrea delle Dame & 2 & 2 & 4 & 2 & 3 & 5 \\
Palazzo Venezia & 2 & 2 & 4 & 1 & 2 & 3 \\
Palazzo Marigliano & 1 & 2 & 3 & 1 & 2 & 3 \\
\hline
\end{tabular}


Table 5. Activities variable scores for the past and current scenarios.

\begin{tabular}{ccccccccc}
\hline & \multicolumn{4}{c}{ Past } & \multicolumn{5}{c}{ Current } \\
\hline Sites & T & I & A & ACT & T & I & A & ACT \\
\hline Santi Marcellino and Festo & 1 & 1 & 1 & 2 & 1 & 1 & 2 & 3 \\
Sant'Andrea delle Dame & 1 & 1 & 1 & 2 & 1 & 2 & 2 & 4 \\
Palazzo Venezia & 2 & 2 & 2 & 6 & 2 & 1 & 2 & 4 \\
Palazzo Marigliano & 1 & 1 & 2 & 3 & 2 & 0 & 2 & 2 \\
\hline
\end{tabular}

Table 6. Soundscape variable scores for the past and current scenarios.

\begin{tabular}{ccccccc}
\hline & \multicolumn{3}{c}{ Past } & \multicolumn{3}{c}{ Current } \\
\hline Sites & SLD & PS & SOU & SLD & PS & SOU \\
\hline Santi Marcellino and Festo & 2 & 3 & 5 & 1 & 3 & 4 \\
Sant'Andrea delle Dame & 2 & 3 & 5 & 2 & 3 & 5 \\
Palazzo Venezia & 2 & 1 & 3 & 2 & 2 & 4 \\
Palazzo Marigliano & 1 & 2 & 3 & 1 & 2 & 3 \\
\hline
\end{tabular}

Table 7. Global results.

\begin{tabular}{ccccccccc}
\hline & \multicolumn{4}{c}{ Past } & \multicolumn{4}{c}{ Current } \\
\hline Sites & HA & ENV & ACT & SOU & HA & ENV & ACT & SOU \\
\hline Santi Marcellino and Festo & 6 & 6 & 2 & 5 & 5 & 6 & 3 & 4 \\
Sant'Andrea delle Dame & 6 & 4 & 2 & 5 & 5 & 5 & 4 & 4 \\
Palazzo Venezia & 2 & 4 & 6 & 3 & 2 & 3 & 4 & 4 \\
Palazzo Marigliano & 3 & 3 & 3 & 5 & 2 & 3 & 2 & 3 \\
\hline
\end{tabular}

The observation of the graph of Figure 10a, shows that the Cloisters present shapes very close to $\mathrm{D}_{\text {shape }}$ in the past $\left(F_{\text {shape }}<0.90\right)$ and a good superimposition between the past and current scenarios. While HA and ENV are still well conserved over the time for both cloisters, it can be seen that, today, the inside activities (ACT) are more intense than in the past, with a general worsening of the soundscape. This is more evident for the cloister of $S$. Andrea delle Dame which current $F_{\text {shape }}$ assumes the value of 1 .

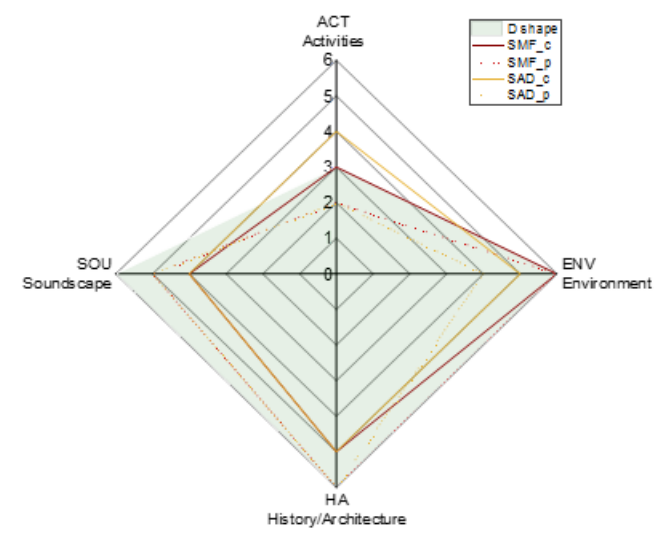

(a)

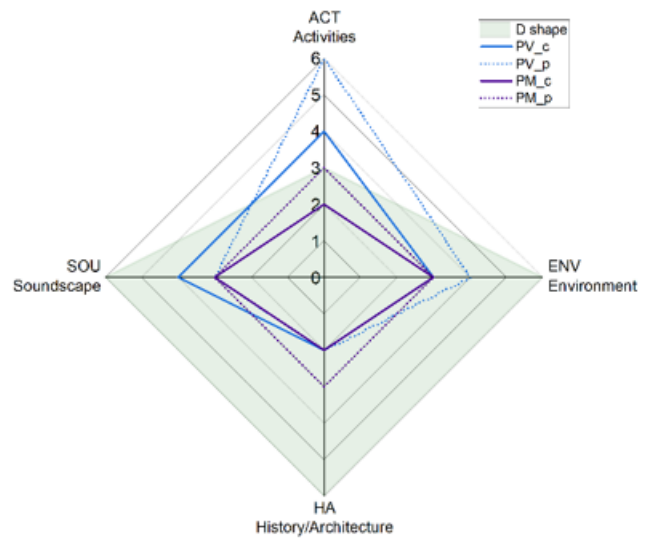

(b)

Figure 10. Diamond graphs.: (a) Cloisters and (b) Courtyards of historical palaces.

On the other hand, both courtyards (Figure 10b) do not show the expected balance among the four variables, nor high levels of $F_{m a g}$ (see Table 8). The most important differences between the past 
and current situations are mainly due to the changing of the variable ACT, which decreases for both the buildings. The most significant changes can be noted in Palazzo Venezia.

Table 8. Results of $F_{\text {shape }}$ and $F_{\text {mag. }}$.

\begin{tabular}{cccccc}
\hline & Current & Past & Current & Past \\
\hline Sites & \multicolumn{2}{c}{ F $_{\text {shape }}$} & \multicolumn{3}{c}{ F $_{\text {mag }}$} \\
\hline Diamond shape & \multicolumn{2}{c}{0.75} & & 54.0 \\
Santi Marcellino and Festo & 0.80 & & 0.73 & 40.0 & 44.0 \\
Sant'Andrea delle Dame & 1.00 & 0.89 & 40.5 & 36.0 \\
Palazzo Venezia & 0.86 & 1.14 & 21.0 & 28.0 \\
Palazzo Marigliano & 0.67 & 1.00 & 12.0 & 18.0 \\
\hline
\end{tabular}

\section{Subjective Survey of PRS and Validation of the Procedure}

The Italian version of the Perceived Restorativeness Scale proposed by Pasini et al. [27], PRS-11, was used and administered by in situ interviews to 40 people (10 per each site) who visited the sites for some reasons. Ninety-five percent of the subjects ranged in age between 18 and 59 years, and 50\% were males. Through an analysis of the results of the PRS-11 (Table 9), it is observed that, while the cloister of Santi Marcellino and Festo still conserve their restoration characteristics for the visitors, Sant'Andrea delle Dame has changed its role over the time, being perceived with low values of Being-Away and Fascination. Lower scores were also obtained for the Coherence and the Scope of the site. Differently, despite the high scores of Fascination and Being-Away, both the palaces showed moderate restorative characteristics.

Table 9. Results of the PRS-11.

\begin{tabular}{cccccc}
\hline Sites & FAS & B-A & COH & SC & PRS-11 \\
\hline Santi Marcellino and Festo & 7.90 & 7.07 & 6.27 & 7.85 & 7.27 \\
Sant'Andrea delle Dame & 5.00 & 4.27 & 3.90 & 4.80 & 4.49 \\
Palazzo Venezia & 6.83 & 7.33 & 4.73 & 5.55 & 6.11 \\
Palazzo Marigliano & 7.63 & 6.87 & 5.37 & 6.25 & 6.53 \\
\hline
\end{tabular}

To facilitate the analytic comparison among the previous results, two additional parameters that measure the distance between the graphic representations of the sites and the Diamond shape were introduced. The values of Distance_F $F_{\text {shape }}$ and Distance_Fmag are shown in Table 10.

$$
\begin{aligned}
& \operatorname{Distance}\left(F_{\text {shape }}\right)=F_{\text {shape }}^{\text {i-th site }}-F_{\text {shape }}^{\text {Diamond shape }} \\
& \operatorname{Distance}\left(F_{\text {mag }}\right)=\frac{F_{\text {mag }}^{\text {Diamond shape }}-F_{\text {mag }}^{- \text {th site }}}{F_{\text {mag }}^{\text {Diamond shape }}}
\end{aligned}
$$

Table 10. Values of parameters Distance_$F_{\text {shape }}$ and Distance_ $F_{m a g}$.

\begin{tabular}{ccc}
\hline Sites & Distance_ $\boldsymbol{F}_{\text {shape }}$ & Distance $\boldsymbol{F}_{\text {mag }}$ \\
\hline Santi Marcellino and Festo & 0.05 & 0.26 \\
Sant'Andrea delle Dame & 0.25 & 0.25 \\
Palazzo Venezia & 0.11 & 0.61 \\
Palazzo Marigliano & -0.08 & 0.78 \\
\hline
\end{tabular}

Figure 11 Displays the Scatter Matrix of the Pearson correlation coefficients among PRS-11, FAS, B-A, COH, SC, Distance_Fshape and Distance_Fmag for the current scenario (see Figure 11). 
A high positive correlation coefficient between Distance_F $F_{\text {shape }}$ and PRS-11 $(R=0.7811)$ in the scatter matrix (Figure 11) showed a good agreement between the Diamond graphic representation of the sites and the results of PRS-11, whereas the results were mainly affected by the higher correlation with Fascination $(R=0.8769)$, Being-Away $(R=0.7346)$ and Coherence $(R=0.7115)$. Weak correlations were found for the Distance $F_{\text {mag. }}$. The best correlation was the positive correlation with the Being-Away (0.5379).

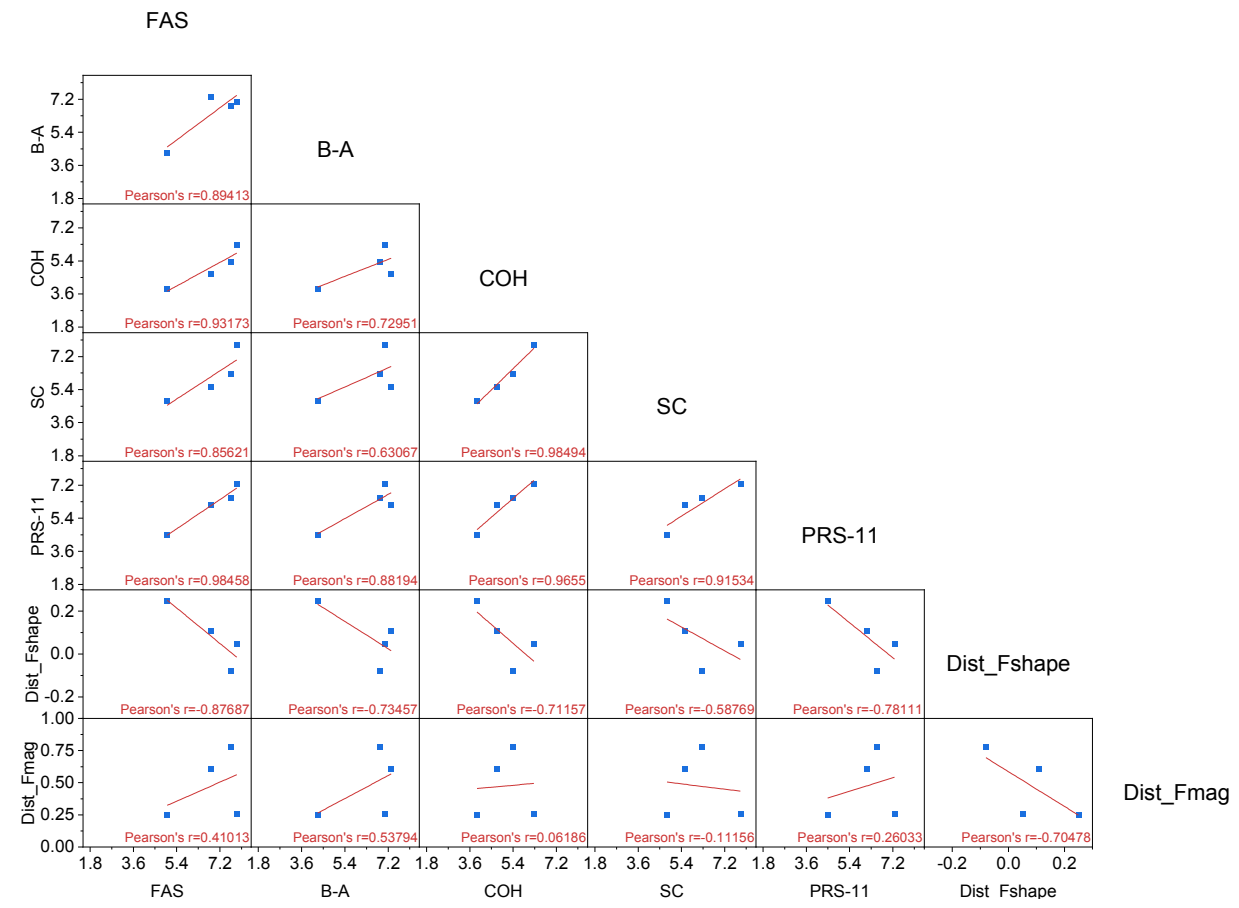

Figure 11. Triangular plot of the scatter matrix of the Pearson's correlation coefficients for the current situation.

\section{Discussion}

Historical cloisters and courtyards in cities can be classified as quiet areas if they show restorative capabilities for the local population. Their use, in this perspective, not only improves the quality of the life and well-being of people, but also contributes to the preservation and valorization of the intangible values of these places. The restorativeness is, however, influenced by both the physical/environmental and the historical/architectural elements.

In this paper we proposed and verified the results of the application of a procedure that summarizes the main dimensions affecting the restorativeness of the individuals, in a graphic representation. This propensity toward the physic and mental restoration of the chosen historic sites, in the past and current years, were estimated and compared through this representation.

The case study of the procedure regarded several cloisters and courtyards of historical palaces located in the center of Naples (Italy). In this ancient city center, the history and present coexist and, single walkers, or small groups of people, citizens and tourists, live along the route of the Decumano Major the most incredible of experiences, immersing themselves in the sounds and loud noises of an authentic and frenetic city, such as Naples.

The procedure and the "Diamond" graphic representation has explored with historical analyses and objective estimation and description of the past and current scenarios through the Historical/Architectural, Environmental, Activities and Soundscape aspects. Although in some parts of the procedure a qualitative approach was used (e.g., to determine the scores of the variables and to estimate the scores in the past scenarios), the graphic representation showed a good agreement with the perceived Restorativeness. This means that the Diamond shape effectively well represents 
highly restorative sites, while deviations from this shape is correlated with a reduced Restorativeness nature. When analyzing the factors that analytically describe the Diamond shape, it was observed how the Distance_F $\mathrm{F}_{\text {shape }}$ resulted in a high positive correlation with the results of the PRS-11 as well as with Fascination. On the contrary, Distance $\mathrm{F}_{m a g}$ showed to have a very weak correlation with it. This means that, rather than the dimension of the Diamond, the most important aspect is the equilibrium among the four main variables. Further applications of this methodology, in more Neapolitan sites but also in sites of others ancient city centres and at different cultures, need to be carried out so as to highlight the limitations, due mainly to the qualitative approach, as well as consider possible future modifications. The existence of sufficient historical traces and literature of the activities is crucial for the characterization of the restorativeness in the past.

With reference to the test site of Sant'Andrea delle Dame, changes in the Diamond shape are due mainly to an increasing of the current Activities inside the cloisters as well as the worsening of the Soundscape. This means that, despite the general conservation of the Environment and History/Architecture, the typology and intensity of the activities are not more compatible with the people restoration, engendering loud and unpleasant sounds. At the same time, the changes of the variable Activities over the time, influenced the conservation of restorative capability for historical sites. While for the Cloister of San Marcellino and Festo, the preservation of its characteristic of restoration can be highlighted, while for Palazzo Venezia the relevant change of their use over the ages has been highlighted, with a general loss of some of its past functions is highlighted.

However, as noted the historical research based on guidebooks and periegetic literature is not be enough in order to get information about the soundscape of the past. Therefore, it is be necessary to extend the research to indirect documentary sources. Further important information could be extracted from the observation of liturgical calendars which describe celebrations, processions or other events held in public spaces; archives of confraternities and workers' guilds and procedural acts, in which it is possible to find information on the annoyances associated with the performance of noisy activities or spontaneous musical practices. Moreover, information about market days, civic customs or temporary uses of the historical city (markets; opening of small shops in historical courtyards etc.) are important when considering what influenced the urban soundscape. Surveys of historical toponymy which have often been significantly altered over the last two centuries, through the naming of streets, previously recognized with the name of the activities that took place there in pre-industrial times, to famous people or events, could also provide information about the historic soundscape of the city. Collaborating with a musicologist could also be important in order to improve the research on the historic urban sound.

In conclusion, the procedure has the potentiality to be applied in other cities with similar urban, historic and social characteristics and it could be the basis for a sustainable and wider project which merges the identification of quiet areas in urban sites and the cultural conservation of historical sites.

Author Contributions: All the authors have read and agree to the published version of the manuscript. Conceptualization, L.M., F.C. and M.M.; Methodology, L.M. and M.M.; Validation, R.A.T. and M.M.; Formal Analysis, M.M.; Investigation, R.A.T., F.C. and M.M.; Data Curation, M.M.; Writing-Original Draft Preparation, R.A.T., F.C. and M.M.; Writing-Review and Editing, R.A.T., F.C., L.M. and M.M.; Visualization, R.A.T., F.C. and M.M.; Supervision, L.M.; Project Administration, M.M. and L.M. All authors have read and agreed to the published version of the manuscript.

Funding: This research received no external funding.

Conflicts of Interest: The authors declare no conflict of interest.

\section{References}

1. Directive, E.U. Directive 2002/49/EC relating to the assessment and management of environmental noise. Off. J. Eur. Commun. 2002, 189, 12-25.

2. European Environment Agency (EEA). Good Practice Guide on Quiet Areas; EEA Technical report N. 4/2014; European Environment Agency (EEA): Copenhagen, Denmark, 2014. 
3. European Environment Agency (EEA). Quiet Areas in Europe. The Environment Unaffected by Noise Pollution; EEA Technical report N. 14/2016; European Environment Agency (EEA): Copenhagen, Denmark, 2016.

4. Brambilla, G.; Maffei, L. Responses to noise in urban parks and in rural quiet areas. Acta Acust. United Acust. 2006, 92, 881-886.

5. Brambilla, G.; Gallo, V.; Asdrubali, F.; D'Alessandro, F. The perceived quality of soundscape in three urban parks in Rome. J. Acoust. Soc. Am. 2013, 134, 832-839. [CrossRef] [PubMed]

6. Tse, M.S.; Chau, C.K.; Choy, Y.S.; Tsui, W.K.; Chan, C.N.; Tang, S.K. Perception of urban park soundscape. J. Acoust. Soc. Am. 2012, 131, 2762-2771. [CrossRef]

7. Payne, S.R.; Bruce, N. Exploring the relationship between urban quiet areas and perceived restorative benefits. Int. J. Environ. Res. Public Health 2019, 16, 1611. [CrossRef]

8. Schafer, R.M. The Book of Noise; Price Milburn Co. Lee: Wellington, New Zealand, 1973.

9. Schafer, R.M. The Tuning of the World; University of Pennsylvania Press: Philadelphia, PA, USA, 1977.

10. Axelsson, Ö.; Nilsson, M.E.; Berglund, B. A principal components model of soundscape perception. J. Acoust. Soc. Am. 2010, 128, 2836-2846. [CrossRef]

11. Watts, G.R. The effects of greening urban areas on the perceptions of tranquility. Urban For. Urban Green. 2017, 26, 11-17. [CrossRef]

12. Dzhambov, A.; Dimitrova, D. Urban green spaces' effectiveness as a psychological buffer for the negative health impact of noise pollution: A systematic review. Noise Health 2014, 16, 157-165. [CrossRef]

13. De Coensel, B.; Vanwetswinkel, S.; Botteldooren, D. Effects of natural sounds on the perception of road traffic noise. J. Acoust. Soc. Am. 2011, 129, 148-153. [CrossRef]

14. Watts, G.; Pheasant, R.; Horoshenkov, K.; Ragonesi, L. Measurement and subjective assessment of water generated sounds. Acta Acust. United Acust. 2009, 95, 1032-1039. [CrossRef]

15. Jeon, J.Y.; Lee, P.J.; You, J.; Kang, J. Perceptual assessment of quality of urban soundscapes with combined noise sources and water sounds. J. Acoust. Soc. Am. 2010, 127, 1357-1366. [CrossRef] [PubMed]

16. Axelsson, Ö.; Nilsson, M.E.; Hellström, B.; Lundén, P. A field experiment on the impact of sounds from a jet-and-basin fountain on soundscape quality in an urban park. Landscape Urban Plang. 2014, 123, 49-60. [CrossRef]

17. Chau, C.K.; Leung, T.M.; Xu, J.M.; Tang, S.K. Modelling noise annoyance responses to combined sound sources and views of sea, road traffic, and mountain greenery. J. Acoust. Soc. Am. 2018, 144, 3503-3513. [CrossRef]

18. Lugten, M.; Karacaoglu, M.; White, K.; Kang, J.; Steemers, K. Improving the soundscape quality of urban areas exposed to aircraft noise by adding moving water and vegetation. J. Acoust. Soc. Am. 2018, 144, 2906. [CrossRef] [PubMed]

19. Chung, W.K.; Chau, C.K.; Masullo, M.; Pascale, A. Modelling perceived oppressiveness and noise annoyance responses to window views of densely packed residential high-rise environments. Build. Environ. 2019, 157, 127-138. [CrossRef]

20. Masullo, M.; Maffei, L.; Pascale, A.; Senese, V.P. An alternative noise mitigation strategy in urban green park: A laboratory experiment. In Proceedings of the Internoise, Hong Kong, China, 27-30 August 2017.

21. Zhang, Y.; Kang, J.; Kang, J. Effects of Soundscape on the Environmental Restoration in Urban Natural Environments. Noise Health 2017, 19, 65-72.

22. Senese, V.P.; Pascale, A.; Maffei, L.; Cioffi, F.; Sergi, I.; Gnisci, A.; Masullo, M. The influence of personality traits on the measure of restorativeness in an urban park: A Multisensory Immersive Virtual Reality study. In Proceedings of the WIRN, Vietri sul Mare, Italy, 13-15 June 2018. in press.

23. Kang, Y.; Kim, E.J. Differences of Restorative Effects While Viewing Urban Landscapes and Green Landscapes. Sustainability 2019, 11, 2129. [CrossRef]

24. Kaplan, S. The restorative benefits of nature: Toward an integrative framework. J. Environ. Psychol. 1995, 15, 169-182. [CrossRef]

25. Hartig, T.; Korpela, K.; Evans, G.W.; Garling, T. A measure of restorative quality in environments. Scand. Hous. Plan. Res. 1997, 14, 175-194. [CrossRef]

26. Laumann, K.; Garling, T.; Stormark, K.M. Rating scale measures of restorativeness components of environments. J. Environ. Psychol. 2001, 21, 31-44. [CrossRef]

27. Pasini, M.; Berto, R.; Brondino, M.; Hall, R.; Ortner, C. How to measure the restorative quality of environments: The PRS-11. Procedia Soc. Behav. Sci. 2014, 159, 293-297. [CrossRef] 
28. Payne, S.R.; Guastavino, C. Exploring the Validity of the Perceived Restorativeness Soundscape Scale: A Psycholinguistic Approach. Front. Psychol. 2018, 9, 2224. [CrossRef] [PubMed]

29. Kaplan, S. Meditation, restoration, and the management of mental fatigue. Environ. Behav. 2001, 33, 480-506. [CrossRef]

30. Von Lindern, E.; Lymeus, F.; Hartig, T. The Restorative Environment: A Complementary Concept for Salutogenesis Studies. In The Handbook of Salutogenesis; Springer: Berlin, Germany, 2017.

31. United Nations Educational, Scientific and Cultural Organization. Recommendation on the Historic Urban Landscape; United Nations Educational, Scientific and Cultural Organization: Paris, France, 2011.

32. The Lancet Arts for health's sake. Lancet 2014, 383, 1100. [CrossRef]

33. Council England. The Value of Arts and Culture to People and Society. An Evidence Review Arts; Council England: London, England, 2014.

34. Hidalgo, M.C.; Berto, R.; Galindo, M.P.; Getrevi, A. Identifying attractive and unattractive urban places: Categories, restorativeness and aesthetic attributes. Medioambiente y Comportamiento Humano 2006, 7, 115-133.

35. Weber, A.M.; Trojan, J. The Restorative Value of the Urban Environment: A Systematic Review of the Existing Literature. Environ. Health Insights 2018, 12, 1-13. [CrossRef]

36. Fornara, F.; Troffa, R. Restorative experiences and perceived affective qualities in different built and natural urban places. In Revitalising Built Environments: Requalifying Old Places for New Uses; Yildiz, H.T., Guney, Y.I., Eds.; Istanbul Technical University: Istanbul, Turkey, 2009; pp. 1-10.

37. Russell, J.A.; Lanius, U.F. Adaptation level and the affective appraisal of environments. J. Environ. Psychol. 1984, 4, 119-135. [CrossRef]

38. Ouellette, P.; Kaplan, R.; Kaplan, S. The monastery as a restorative environment. J. Environ Psychol. 2005, 25, 175-188. [CrossRef]

39. Grossi, E.; Blessi, G.T.; Sacco, P.L. Magic Moments: Determinants of Stress Relief and Subjective Wellbeing from Visiting a Cultural Heritage Site. Cult. Med. Psychiatry 2019, 43, 4-24. [CrossRef]

40. Maffei, L.; Toma, R.A.; Masullo, M. Objective and subjective assessment of pockets of quiet inside historical urban areas. In Proceedings of the INTER-NOISE 2018 Impact of Noise Control Engineering, Chicago, IL, USA, 26-29 August 2018.

41. Maffei, L.; Masullo, M.; Oliviero, A. Quiet areas inside historical city centers. In Proceedings of the Internoise 2017, INCE, Hong Kong, China, 27-30 August 2017.

42. Akin Guler, G.; Ozcevik Bilen, A.; Masullo, M.; Maffei, L. The potential of being the quiet plans of the Khans Courtyards in Istanbul Historic Peninsula. In Proceedings of the 23rd International Congress on Acoustics, Aachen, Germany, 9-13 September 2019.

43. Celano, C. Delle Notizie del bello, dell'antico e del curioso della città di Napoli Giornata Prima e Terza, Napoli; Stamperia di Gianfrancesco Paci: Napoli, Italia, 1792.

44. Galasso, G. Intervista sulla storia di Napoli; Editore Laterza: Napoli, Italia, 2018.

45. Anna, M. Rao, Il Regno di Napoli nel Settecento; Guida Editori: Napoli, Italia, 1983; p. 58.

46. Rossi, P. Monasteri e Conventi a Napoli nella seconda metà dell'Ottocento: analisi delle stratificazioni architettoniche, ipotesi di progetto e nuove funzioni, in I luoghi Della Memoria II. Istituti Religiosi Femminili a Napoli dal 1600 al 1861; Valerio, A., Ed.; Voyage Pittoresque: Napoli, Italia, 2007; pp. 37-76.

47. Nicolella, D. I Cento Chiostri di Napoli Guida Storico Artistica; Edizioni Scientifiche Italiane: Napoli, Italia, 1986.

48. Strazzullo, F. Palazzo di Capua; Arte Tipografica: Napoli, Italia, 1995.

49. De Divitiis, G.P. Il Napoletano Palazzo di Venezia; Grimaldi \& Cicerano: Napoli, Italia, 1980.

50. Di Girolamo, R. Il Giardino Dipinto; Cromografica: Roma, Italia, 2014.

51. Fratta, A. Il complesso di San Marcellino Storia e Restauro; Fridericiana Editrice Universitaria: Napoli, Italia, 2000.

52. Costituzione delle Monache del Monastero di Sant'Andrea di Napoli; Nicolò Nalo: Napoli, Italia, 1748.

53. Amirante, G. Il monastero di Sant'Andrea delle Dame in Università degli Studi della Campania Luigi Vanvitelli; Giannini Editore: Napoli, Italia, 2018; pp. 115-121.

(C) 2020 by the authors. Licensee MDPI, Basel, Switzerland. This article is an open access article distributed under the terms and conditions of the Creative Commons Attribution (CC BY) license (http://creativecommons.org/licenses/by/4.0/). 